\title{
Cutaneous Melanoma Pathologic Regional Lymph Nodes TNM Finding v8
}

National Cancer Institute

\section{Source}

National Cancer Institute. Cutaneous Melanoma Pathologic Regional Lymph Nodes TNM

Finding v8. NCI Thesaurus. Code C136953.

A pathologic finding about one or more characteristics of cutaneous melanoma,

following the rules of the TNM AJCC v8 classification system as they pertain to staging of regional lymph nodes. The TNM pathologic and clinical regional lymph nodes classifications of cutaneous melanoma are not the same. TNM pathologic findings are based on the microscopic examination of the regional lymph nodes, usually detected by lymphatic mapping and sentinel lymph node biopsy (clinically occult regional lymph node metastasis). (from AJCC 8th Ed.) 